\section{ILLNESS IN GENERAL PRACTICE}

BY

\section{JOHN PEMBERTON, M.D., M.R.C.P.}

(From the Department of Medicine, University of Sheffield)

We are fortunate in this country in possessing elaborate and reliable information on the causes of mortality, but with the greater emphasis now being placed on the early diagnosis and the prevention of illness more data are required on morbidity.

This need is being partially met by the surveys of sickness carried out by the Social Survey for the Ministry of Health, whose first report appeared in 1946 (Slater, 1946). The information collected by the Social Survey is obtained by non-medical workers, and while it gives valuable information about the general incidence and trends of illness based on broad diagnostic groups it cannot be expected to provide the detailed information about illness in the community which only certification by doctors can yield. Detailed information on the causes of incapacity from sickness amongst the insured population of Scotland was published by the Department of Health for Scotland (1939), and provides a wealth of morbidity data about this population group in the year 1936-7.

The following survey was undertaken to obtain information about the types and relative frequency of illnesses which lead people to consult their general practitioner.

\section{Scope of the Survey}

Eight general practitioners living in Sheffield or its neighbourhood recorded the age, sex, and diagnosis of all the patients, panel and private, who consulted them in the course of one winter week, February 1 to 7 , and one summer week, June 28 to July 4, in 1947. They also indicated whether the patient was seen in the surgery or the patient's home and which cases it was necessary to refer to a hospital or local authority clinic.

The total number of consultations was $4,656(2,816$ in the winter week and 1,840 in the summer week). Only seven of the doctors were able to carry out the summer week survey, as the eighth had left the district. Six of the practices were within the boundaries of the city of Sheffield, one was in Rotherham, and one was situated in the neighbouring mining-agricultural town of Clowne.

Of the 4,656 consultations, 3,041 (65.2\%) were held in the doctor's surgery, $1,542(33.2 \%)$ in the patient's home, and 73 patients $(1.6 \%)$ sent relatives to the doctor on their behalf.

The average number of consultations carried out by each doctor was 353 in the winter week and 265 in the summer week. In $2 \%$ of the consultations the patient was referred to a hospital out-patient department, in $0.16 \%$ to an in. patient department, and in $0.2 \%$ to a local authority clinic.

Age and Sex.-Table I shows the distribution of the patients by age group and sex. The total numbers of

TABLE I.-Percentage of Patients Falling in Each Age Group, Males and Females

\begin{tabular}{c|c|c|c|c|c|c|c|c|c|c|c}
\hline Years: & $0-$ & $5-$ & $15-$ & $20-$ & $30-$ & $40-$ & $50-$ & $60-$ & $70-$ & $80-$ & All Ages \\
\hline $\begin{array}{l}\text { Male } \\
\text { Female }\end{array}$ & $11 \cdot 6$ & $\begin{array}{r}8 \cdot 0 \\
\text { U.4 }\end{array}$ & $\begin{array}{r}4 \cdot 5 \\
6 \cdot 9\end{array}$ & $\begin{array}{r}12 \cdot 6 \\
18 \cdot 5\end{array}$ & $\begin{array}{r}15 \cdot 7 \\
15 \cdot 4\end{array}$ & $\begin{array}{r}15 \cdot 0 \\
13 \cdot 8\end{array}$ & $\begin{array}{r}14 \cdot 0 \\
10 \cdot 2\end{array}$ & $\begin{array}{r}11 \cdot 3 \\
9 \cdot 0\end{array}$ & $\begin{array}{r}6 \cdot 0 \\
6 \cdot 8\end{array}$ & $\begin{array}{r}1 \cdot 7 \\
3 \cdot 2\end{array}$ & $\begin{array}{r}2,301 \\
2,326 \\
29\end{array}$ \\
\hline
\end{tabular}

males and females were nearly equal, but in certain age groups one sex predominated. Females exceeded males in the age group 15-29 mainly because of consultations for obstetrical or gynaecological conditions. Males were in excess in the age period 40-69 but not after that age.

\section{The Illnesses}

Table II shows the main causes of illness found in the two-weeks survey and their relative frequency. The

TABLE II.-Incidence of the Different Types of Illness

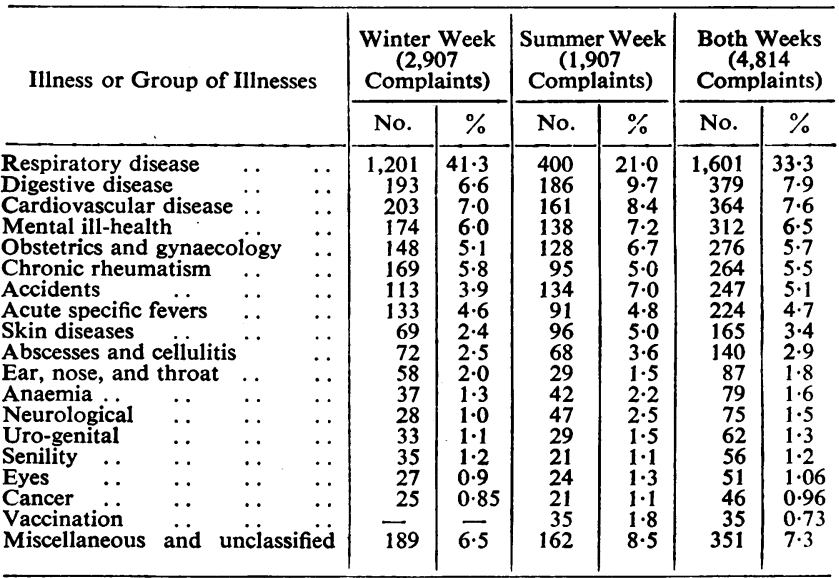

number of diagnoses $(4,814)$ exceeds the number of consultations $(4,656)$ because some patients were suffering from more than one complaint.

Respiratory Disease.-The respiratory group of illnesses was by far the largest, accounting for $41.3 \%$ of the diagnoses in the winter week and $21 \%$ in the summer week. The frequency of the different varieties of respiratory illness is shown in Table III. In the winter week influenza

TABLE III.-Analysis of the Respiratory Illnesses

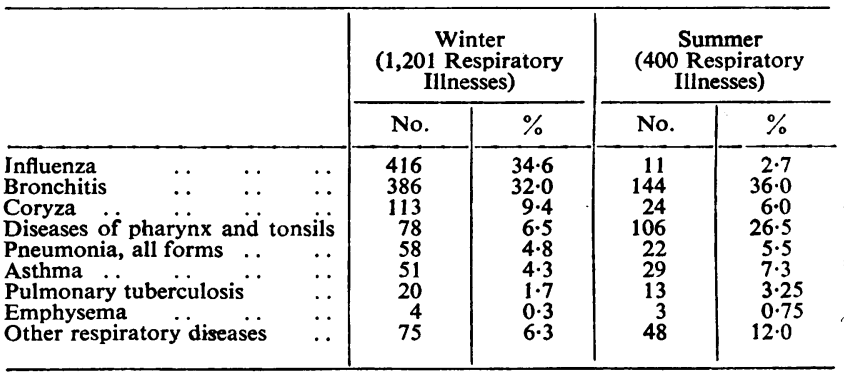

accounted for $34.6 \%$ and bronchitis for $32 \%$ of the respiratory illness. It so happened that a minor epidemic of influenza A reached its peak during this week (StuartHarris, 1947). In the summer week bronchitis still accounted for $36 \%$ of the respiratory illness, while the percentage attributable to influenza had fallen to $2.7 \%$. The fall in the number of influenza cases in the summer week has the effect of making the percentage incidence of the other causes of respiratory illness disproportionately high. Theie were, however, more cases of disease of the pharynx or tonsils in the summer week. The poliomyelitis epidemic was gaining ground at this time, and it is possible that some of these pharyngeal conditions represented abortive attacks, of that disease. Taking the winter and summer weeks together, bronchitis was the commonest complaint for which medical aid was sought from the general practitioners. It accounted for $11 \%$ of all the consultations.

Digestive Diseases.-These came next in frequency. In this group $68 \%$ were cases of dyspepsia of various types, excluding cancer. The other chief complaints in order 
were diarrhoea and enteritis, disorders of the colon, hernia, and appendicitis.

Cardiovascular Disease.-The cardiovascular group, which was the third largest, was subdivided as follows: essential hypertension and cerebrovascular accidents, $37 \%$; coronary disease, $14 \%$; rheumatic heart disease, $12 \%$; other diseases of the heart, $30 \%$; and other diseases of the blood vessels, $7 \%$. "Other diseases of the heart" included the rather ill-defined condition "myocarditis." Some of these cases should perhaps have been assigned to the coronary disease group.

Mental Ill-health.-Cases of mental ill-health consisted of psychoneurosis $93.6 \%$, psychosis $6.1 \%$, and mental deficiency $0.3 \%$.

Obstetrics and Gynaecology.-In this group 36\% were antenatal consultations, $31 \%$ gynaecological complaints, $10 \%$ menopausal disturbances, $9.4 \%$ post-natal visits, $5.4 \%$ abortions, and $5 \%$ confinements.

Chronic Rheumatism.-Under this heading, which accounted for $5.5 \%$ of the diagnoses, were included lumbago, sciatica, fibrositis, rheumatoid arthritis, and osteoarthritis.

Accidents.-Of the accidents $18 \%$ were fractures, $9 \%$ "strains, and $4 \%$ burns or scalds. The remaining $67 \%$ came under the heading "other accidents."

- Acute Specific Fevers.-Of the 224 cases in this group ' $82 \%$ were measles, $9 \%$ chicken-pox, $4 \%$ whooping-cough, $3 \%$ German measles, $1 \%$ scarlet fever, and $0.9 \%$ mumps.

\section{Preventive Medicine}

No patients in this series consulted their doctors for a routine health examination or for advice on the preservation of their health. A certain amount of advice was given by the doctors concerned with regard to the prevention of further illnesses, but the only examples of purely preventive work which were recorded were the 99 antenatal consultations and 35 vaccinations. Together, these constituted $2.9 \%$ of the total consultations. No consultations came under the heading of forensic medicine.

- From this survey it would seem that the most important classes of disease which the general practitioner is called upon to treat are the respiratory, digestive, cardiovascular, and psychological diseases in that order, followed by obstetric and gynaecological conditions, chronic rheumatism, and accidents.

- The low incidence of psychological complaints $(6.5 \%)$ was commented upon by two of the doctors participating in the survey. This may have been due partly to the fact that in the winter week the weather was very severe and may have discouraged a number of psychoneurotics from attending (although the summer figure was very little higher), and partly to the inclusion of some of these cases under other headings, such as "dyspepsia" or " rheumatism."

- In amalgamating the diagnoses of a number of doctors the different criteria employed might lead to the grouping

TABLE IV.-Proportion of Each Doctor's Diagnoses Falling in the Selen Main Diagnostic Groups (winter and summer combined)

\begin{tabular}{|c|c|c|c|c|c|c|c|c|}
\hline Diagnostic Group & $\begin{array}{c}\text { Dr. } \\
\text { A } \\
\%\end{array}$ & $\begin{array}{c}\text { Dr. } \\
\mathbf{B} \\
\%\end{array}$ & $\begin{array}{l}\text { Dr. } \\
\text { C } \\
\%\end{array}$ & $\begin{array}{l}\text { Dr. } \\
\text { D } \\
\%\end{array}$ & $\underset{\%}{\mathbf{E}} \underset{\%}{\mathbf{E}}$ & $\begin{array}{c}\text { Drs. } \\
\text { F \& } \mathbf{G} \\
\end{array}$ & $\begin{array}{l}\text { Dr. } \\
\mathbf{H} \\
\%\end{array}$ & $\begin{array}{c}\text { All } \\
\text { Doctors } \\
\%\end{array}$ \\
\hline $\begin{array}{l}\text { Respiratory disease } \\
\text { Digestive disease } \\
\text { Cardiovascular disease } . . \\
\text { Mental ill-health } \\
\text { Obstetrics and gynaeco- } \\
\text { logy }\end{array}$ & \begin{tabular}{|r|}
28.0 \\
6.7 \\
12.5 \\
5.5 \\
7.3
\end{tabular} & $\begin{array}{r}27.2 \\
8.9 \\
11.8 \\
3.1 \\
5.8\end{array}$ & $\begin{array}{r}42.5 \\
9.6 \\
3.3 \\
8.4 \\
3.6\end{array}$ & $\begin{array}{r}36.8 \\
9.0 \\
5.5 \\
8.1 \\
6.4\end{array}$ & $\begin{array}{r}30.2 \\
7.3 \\
5.5 \\
6.0 \\
2.9\end{array}$ & $\begin{array}{r}31 \cdot 2 \\
6 \cdot 8 \\
9 \cdot 9 \\
7 \cdot 7 \\
7 \cdot 3\end{array}$ & $\begin{array}{r}37.0 \\
7.6 \\
5.4 \\
2.9 \\
6.0\end{array}$ & $\begin{array}{r}33.4 \\
7.9 \\
7.6 \\
6.5 \\
5.7\end{array}$ \\
\hline $\begin{array}{l}\text { Chronic rheumatism } \\
\text { Accidents }\end{array}$ & $\begin{array}{l}3 \cdot 6 \\
2 \cdot 6\end{array}$ & $\begin{array}{l}7 \cdot 2 \\
3 \cdot 9\end{array}$ & $\begin{array}{l}5 \cdot 0 \\
3 \cdot 3\end{array}$ & $\begin{array}{l}5 \cdot 2 \\
3 \cdot 6\end{array}$ & $\begin{array}{c}7 \cdot 7 \\
13 \cdot 5 *\end{array}$ & $\begin{array}{l}4 \cdot 5 \\
3 \cdot 4 \\
\end{array}$ & $\begin{array}{l}6 \cdot 2 \\
5 \cdot 0 \\
\end{array}$ & $\begin{array}{l}5 \cdot 5 \\
5 \cdot 1\end{array}$ \\
\hline Total no. diagnoses & 494 & 415 & 584 & 895 & 749 & 1,190 & 487 & 4,814 \\
\hline
\end{tabular}

*/This practice was in a mining district. together of conditions which are in fact distinct. The frequency with which the different practitioners diagnosed similar conditions is shown in Table IV, and their correspondence suggests that the diagnostic criteria used by the doctors concerned were similar.

\section{Discussion}

It is interesting to compare the pattern of morbidity as revealed in the present survey with a somewhat similar analysis carried out in Sheffield by Calvert Holland in 1843. He records his attempt "to ascertain the nature of the diseases prevailing amongst the working classes" in Sheffield, "from the books of the surgeons at the poorhouse." His analysis of the illnesses of a random sample of 200 males whose ages ranged from 20 to 74 years is shown in Table V. No close comparison with the present

TABLE V.-Dr. Calvert Holland's Analysis of 200 Cases of Sickness in Men Living in Sheffield in 1843

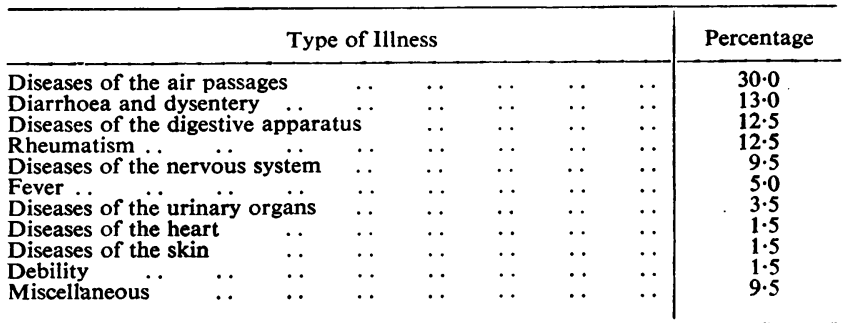

series is possible, as Holland's cases consisted only of adult males from the "labouring classes." Nevertheless it is interesting to note that the incidence of respiratory disease in his survey, as in the present one, heads the list- "diseases of the air passages " accounting for $30 \%$ of his series of cases, compared with $34 \%$ in the present series. The high incidence of diarrhoea and dysentery at that time compared with the present was no doubt largely due to the deficient sanitary arrangements which then prevailed. Digestive disease and rheumatism figure high in Holland's survey, as in the present one ; on the other hand, cardiovascular disease was relatively unimportant. This may be attributed to the fact that only 29 of his 200 patients were over 50 years of age. He also tells us that the mean duration of life in Sheffield at that time was 24.12 years. At that time the chances of a baby living to a "cardiovascular age" were in fact not great.

The pattern of morbidity has changed over the last hundred years, but respiratory disease still dominates the picture. In this group, cases of bronchitis are numerically the most important.

Although the diagnosis of "bronchitis" is not always precise, the condition or group of conditions to which it refers is clearly of great medical and social importance as shown by this and other surveys. Thus in the report on incapacitating sickness in the insured population of Scotland it accounted for $6.57 \%$ of the total days of incapacity and was exceeded only by influenza.' Gafafer (1944), analysing the causes of sickness absence among 293,960 male industrial workers in the United States, found that bronchitis was responsible for $7.5 \%$ of all absences, again being exceeded only by influenza.

The distribution of cases of bronchitis in the present survey by sex and age group is shown in the accompanying Chart, where it is compared with the notifications of pulmonary tuberculosis in Sheffield in 1947 (Roberts, 1947). In adult life the sex-age morbidity pattern of the two diseases is somewhat similar. Females predominate in the first part of working life and males in the later part. Adverse occupational conditions are known to influence the incidence 
of tuberculosis. It seems highly probable that occupational factors are also concerned to an important extent in the aetiology of bronchitis.

One of the general practitioners taking part in the present survey wrote: "I feel that the specialized fields of the profession have little conception of the actual work that is done by the general practitioners, and too much attention is paid to fields of medicine which the future general practitioner is rarely if ever called upon to practise."

The present survey does indeed suggest that the student who intends to become a general practitioner may spend a disproportionate amount of time in examining and studying relatively rare diseases. He would benefit from seeing more cases of minor illness than he can hope to find in a teaching hospital and from more opportunities of seeing

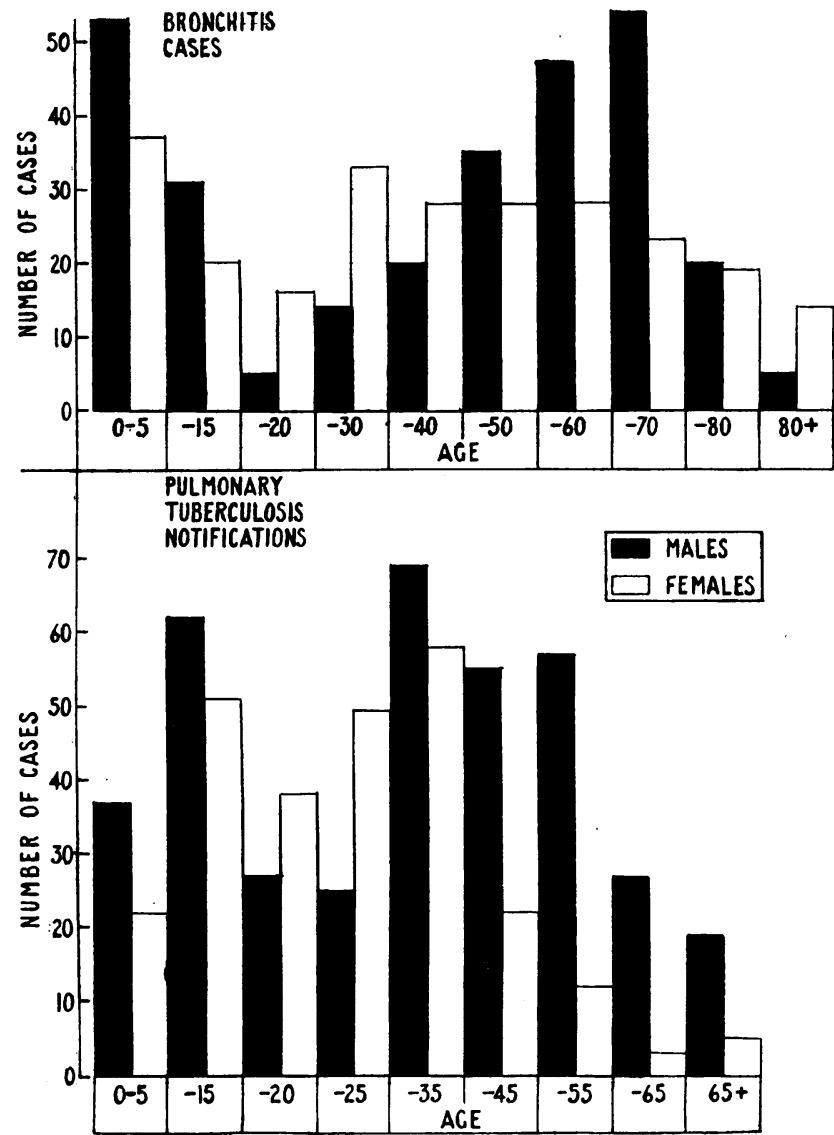

Distribution of cases of bronchitis by sex and age group, compared with the notifications of pulmonary tuberculosis in Sheffield in 1947

disease in its early stages. Some experience in the treatment of the chronic sick and of infirm old people in the home would also be of value to him. Suitably staffed health centres and home visiting from these centres might in the future be used with advantage for the demonstration of such cases to the medical student. In the health centres he could also learn to appreciate the opportunities for practising preventive medicine which occur in general practice.

\section{Summary}

The 4,656 consultations undertaken by eight general practitioners in one winter and one summer week are analysed by sex, age, and diagnosis.

Bronchitis was found to be the commonest condition in summer and in winter for which medical advice was sought. accounting for $11 \%$ of all cases.

The relation between the work done in general practice and the training of medical students is briefly considered.
The following general practitioners, by their careful collection of data, made this survey possible: Drs. B. Droller, H. Droller, C. H. Foggitt, M. Jacob, R. B. Knowles, G. E. Tilsley, W. Toms, and E. Zadik. I wish to thank all of them for allowing me to use their records and for their suggestions with regard to the interpretation of the figures. The severe frosts and heavy snowfalls made the work particularly difficult during the winter week. I am indebted to Professor C. H. Stuart-Harris for helpful advice and criticism, and to Miss B. I. Richardson for valuable assistance in the analysis of the data.

\section{REFERENCES}

Department of Health for Scotland (1939). Seventh Report on Incapacitating Sickness in the Insured Population of Scotland, July 1, 1936, to June 30, 1937. H.M.S.O.. Edinburgh.

Gafafer, W. M. (1944). Publ. Hlth Rep..Wash., 59, 1267.

Holland, G. Calvert (1843). The Vital Statistics of Sheffield. London. Roberts, L. (1947). Annual Report on the Health of the City of Sheffield.

Slater, P.,(1946). "Survey of Sickness, October, 1943-December, 1945." Ministry of Health

Stuart-Harris, C. H. (1947). British Medical Journal, 2, 994.

\section{AFEBRILE CASES OF MELIOIDOSIS}

\author{
BY
}

\section{R. GREEN, M.D., D.Sc. \\ AND}

D. S. MANKIKAR, M.B., B.S.

(From the Institute for Medical Research, Kuala Lumpur, Malaya)

Recovery from infection with Pfeifferella whitmori is rare, the death rate being about $95 \%$, and cases of melioidosis with freedom from marked constitutional symptoms are rarer still. The case history of an afebrile patient observed in Malaya in September, 1941, is given below. He had a localized infection with $P f$. whitmori in a cervical gland, but remained free from general symptoms. He was treated by aspiration of the gland abscess, and when this refilled he was apparently cured by treatment with sulphapyridine. His response to the drug was in keeping with the findings of investigators from 1943 onwards-of which a brief review is given. Reference is made to five other afebrile: cases of melioidosis observed in South-East Asia. The in vitro effects on Pf. whitmori of newer antibiotics such as streptomycin, "polymyxin," and "chloromycetin" are. also described and compared with penicillin.

\section{Case History}

A male Indian artisan aged 30 was admitted to hospital in, Kuala Lumpur during September, 1941, for treatment of quartan malaria. While in hospital a swelling of one of the, cervical glands was noted. This was painful and tender, but was relieved somewhat by glycerin and ichthyol dressings., After receiving quinine treatment for his malaria he had no fever on the fifth, sixth, and seventh days and was discharged, at his own request. He returned to work, but one month later was readmitted to hospital because of further pain and swelling in the cervical gland, which by this time was fluctuating in the centre. He had no fever on readmission or during his six-weeks stay in hospital. The swelling was aspirated on the second day, after readmission and thick mucoid pus was withdrawn. On culture the pus yielded a pure growth of Pf. whitmori.

A guinea-pig which was injected with $0.03 \mathrm{ml}$. of a peptone* water culture of the patient's organism died within sixty hours, the animal's skin showing intense oedema, with com: mencing haemorrhagic necrosis at the site of inoculation. When recovered from the pericardial fluid of the dead guinea-pig and cultured on glycerin agar the organism showed some intensification of its original rugose growth. This type of growth has beerr shown by Nicholls (1934) to be associated with the more virulent variant of $P f$. whitmori-in distinction to the mucoid type. 